\title{
Analysis of sound absorption of hollow tube absorbers
}

\author{
Fazlin A. Khair', Azma Putra ${ }^{2}$, Mohd Jailani M. Nor ${ }^{2}$ and M.Z. Selamat ${ }^{1}$ \\ ${ }^{1}$ Faculty of Mechanical Engineering, Universiti Teknikal Malaysia Melaka, \\ Hang Tuah Jaya, Durian Tunggal Melaka 76100, Malaysia \\ Email: fazlinabdkhair@ student.utem.edu.my, zulkeflis@utem.edu.my \\ ${ }^{2}$ VibroResearch Group, Centre for Advanced Research on Energy (CARe), \\ Universiti Teknikal Malaysia Melaka, \\ Hang Tuah Jaya, Durian Tunggal Melaka 76100, Malaysia \\ Email: azma.putra@utem.edu.my,jai@utem.edu.my
}

\begin{abstract}
This paper discusses the acoustic performance of absorbers constructed using hollow tube structures. Tubes made of polypropylene plastic utilising waste from lollipop sticks were used in this study. The absorption coefficient was tested using the impedance tube method for three different structure arrangements, namely parallel (axial) or perpendicular (transverse and crossed transverse) directions subject to sound incidents on the length of the tubes. The effect of the length or layer thickness of the structures, air gap behind the sample and also introduction of fabric were investigated. The results revealed that the tubes in transverse and crossed transverse arrangements showed greater absorption coefficients compared to the axial arrangement. For a layer thickness of $2 \mathrm{~cm}$ and $3 \mathrm{~cm}$, the absorption coefficients were almost unity and the average absorption coefficients were 0.6 above peak frequency. The presence of air gaps shifts the absorption peak to a lower frequency. Enhancements on absorption coefficients in axial arrangements were obtained by introducing fabric covering the front and/or back of the sample.
\end{abstract}

Keywords: Hollow tube, sound absorber, acoustic material, absorption coefficient.

\section{INTRODUCTION}

Sound absorber materials which are widely used in industries and building sectors are mostly made of synthetic fibres. Analysis from Life Cycle Assessment (LCA) by Asdrubali, Schiavoni [1] showed that these synthetic fibres such as mineral wool, foam glass, and glass fibre [2-4] contribute to negative effects on the environment and human health. Natural 'green' materials thus have become alternative sources for a greener environment. Several works have been published with regards to the potential of natural materials as sound absorbing materials. Putra, Abdullah [5] studied sound absorption of paddy waste fibres. Good absorption coefficient of 0.9 was found at mid to high frequency. In a similar study, sugarcane waste fibres were also found to have an absorption coefficient of up to 0.7 above $1.5 \mathrm{kHz}$ [6]. Eriningsih [7] showed that ramie waste without alkali process recorded a high sound absorption coefficient of 0.8 at $1.6-$ $3.2 \mathrm{kHz}$. [8] observed that samples of coconut fibres with foam had good acoustic properties of up to 0.93 at a frequency of $1.4 \mathrm{kHz}$. Kim, Cho [9] constructed a multilayer of fibrous materials from mulberry papers and coconut fibres in a helical-like shape. By winding the fibrous papers, the frictional contact between the layers could be increased 
and the absorption coefficients could achieve above 0.75 at a frequency range of 1-6.4 kHz. Ersoy and Küçük [10] compared the acoustic properties of tea leaf fibres, polyester and polypropylene based non-woven fibres. Results showed that tea leaf fibres of a 10 $\mathrm{mm}$ thickness backed with woven cotton cloth were better in absorbing sound compared to polyester and polypropylene based non-woven fibres with an average absorption coefficient of 0.8 at a frequency range of $4.5-6.3 \mathrm{kHz}$. Veerakumar and Selvakumar [11] studied the acoustic performance of kapok fibres. It was shown that by reducing the thickness of compressed kapok fibres, greater absorption coefficient could be obtained. The absorption coefficient was recorded at 0.96 between $250 \mathrm{~Hz}$ to $2 \mathrm{kHz}$.Ismail, Ghazali [12] and Zulfian and Sajidin [13] studied fibres from palm sugar trees. The measured absorption coefficient on average was 0.9 at a frequency of $800 \mathrm{~Hz}$ to $2 \mathrm{kHz}$.

Several studies have also been conducted utilising coir fibres as sound absorbers. Fouladi, Ayub [14] showed that the absorption coefficient of 0.8 could be achieved from mid to high frequency for samples of coir fibres with a $45 \mathrm{~mm}$ thickness. Performance at a lower frequency could be improved by introducing a perforated plate at the front layer of the sample [15, 16]. Ying, Putra [17] studied multilayer fibres consisting of kenaf and coir fibres. The addition of kenaf fibres improved the sound absorption of coir fibres [18, 19]. Sound panels made from vegetable fibres also showed promising results for use as sound absorbing materials [20]. Francesco, Francesco [21] investigated tropical plants such as fern, baby tears, begonia, maiden hair fern and green ivy. Results showed that good absorption coefficients which were almost of unity were obtained at a frequency range of $0.8 \mathrm{kHz}-1.6 \mathrm{kHz}$ as the density of ferns and baby tears increased. Bastos, de Melo [22] measured coconut, palm, sisal and acai using scaled reverberation chamber. All the four types of vegetable fibres possessed good absorption coefficients of above 0.5 and also passed the flammability, ageing, odour and fungal tests.

Several works on natural materials of non-fibrous type have also been published. Asdrubali, D'Alessandro [23] investigated the acoustic performance of reed species, Phragmites australis. The cut reeds were brought together to form a cylindrical shape using adhesive tape. Although the holes of the reeds were blocked by adhesive tape, they still proved to be good sound absorbers with an absorption coefficient above 0.5. The absorption was almost constant above $400 \mathrm{~Hz}$. Similar studies have also been conducted by [24] and Khair, Putra [25], [26] regarding the potential of the hollow structure of natural reeds as sound absorbers. Reeds in both axial and transverse arrangements are good in absorbing sound with absorption coefficients above 0.9 due to the non-uniformity of its inner and outer side of hollow structure which result in greater frictional losses. This study was duplicated by Putra, Khair [27] using bamboo structures from a species, Bambusa Multiplex which had a relatively smaller diameter. In this paper, the same hollow tube-like structures were studied, utilising plastic materials from wasted lollipop sticks in an effort to reduce plastic disposal in landfills and eventually save the environment. The performance of sound absorption for normal sound incidence was measured. Several parameters including the different arrangements of samples, different lengths, introduction of air gaps and effects of fabric covers were tested and discussed.

\section{METHODS AND MATERIALS}

In this study, hollow tube structures used as sound absorbing material were made of plastic, i.e. polypropylene (PP) utilising waste from lollipop sticks. The structure had an outer diameter of $0.35 \mathrm{~cm}$, an inner diameter of $0.15 \mathrm{~cm}$ and a density of $1000 \mathrm{~kg} / \mathrm{m}^{3}$. The structures were tested in three different arrangements, namely axial, transverse and 
crossed transverse arrangements as shown in Figure 1. For the axial arrangement, the tubes were cut into $2 \mathrm{~cm}$ and $3 \mathrm{~cm}$ lengths and hollow cross sections of the tubes faced the sound incident. For transverse and crossed transverse arrangements, the samples were cut so that they could be fixed into the diameter of the tubes and arranged layer by layer of $2 \mathrm{~cm}$ and $3 \mathrm{~cm}$ thickness. For crossed transverse arrangement, the tubes were arranged the same as in the transverse arrangement, but each layer of the tubes was positioned perpendicular to one another. The effect of fabric covers at the front and back surfaces of the sample were also measured as shown in Figure 2. The fabric was made from felt of 2 mm thickness.

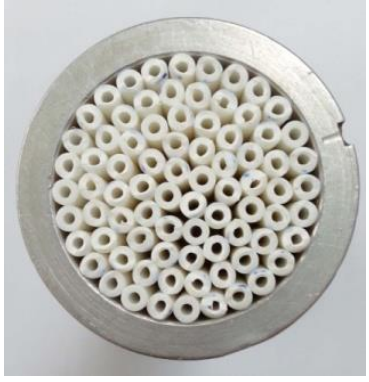

(a)

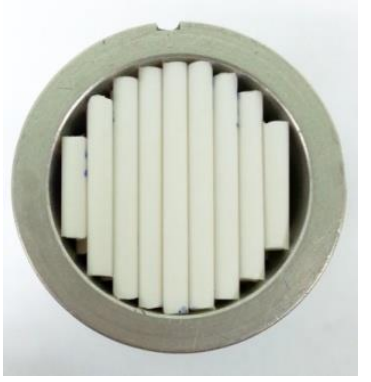

(b)

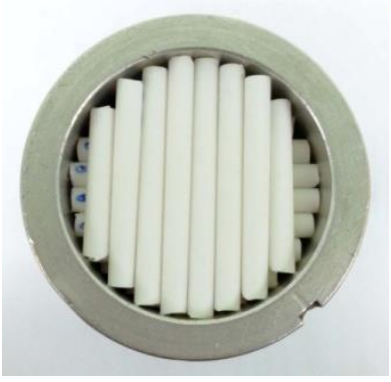

(c)

Figure 1. Arrangement of the hollow tube structures: (a) axial, (b) transverse and (c) crossed transverse.

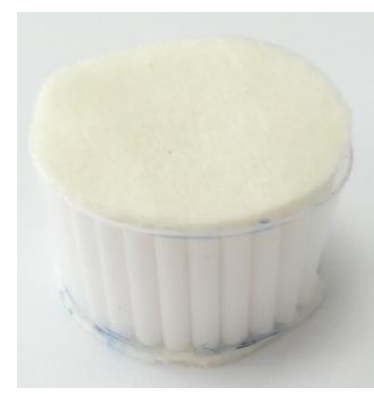

Figure 2. Samples of structures covered with fabric.

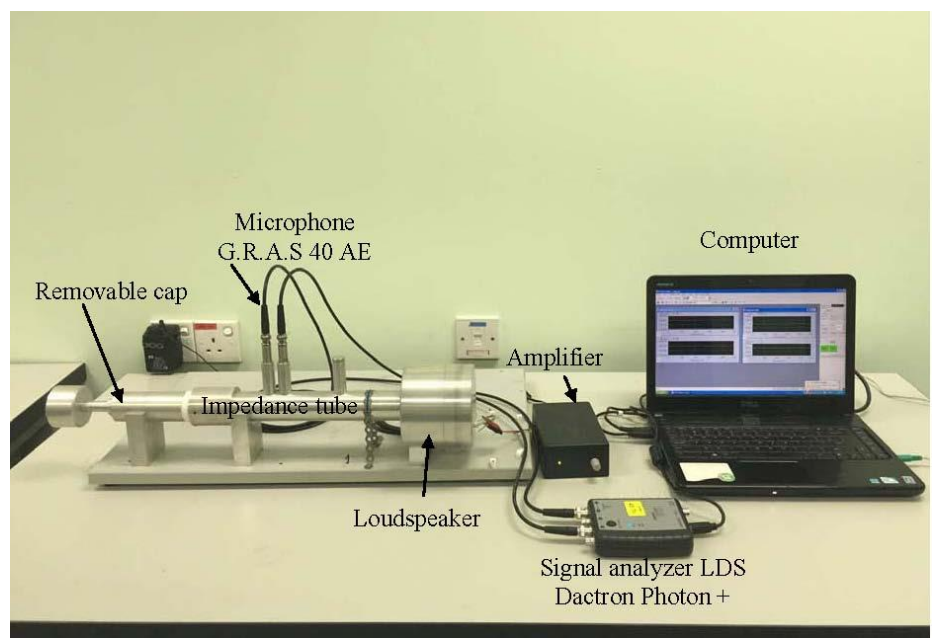

Figure 3. The set-up of the impedance tube measurement. 
Measurement of the sound absorption coefficient employed the impedance tube method in accordance with ISO 10534-2 (2001) [28]. The experimental set-up is shown in Figures 3 and 4 . The tube has a diameter of $33.3 \mathrm{~mm}$. Thus it is only valid to measure absorption coefficients of a frequency range between $0.5-4.5 \mathrm{kHz}$. The sample was located at the end of the tube, while at the other end of the tube was a loudspeaker generating white noise into the tube. Two 1/2" pre-polarized free field G.R.A.S microphones type 40E equipped with pre-amplifier recorded the incident and reflected sound pressure in the impedance tube. Sound calibrator of type B\&K 4231 was used to calibrate the sensitivity of the microphones at $1 \mathrm{kHz}$. The LDS Photon+ signal analyzer recorded and post processed the measured signals and sound absorption coefficients were obtained via computing using MATLAB software.

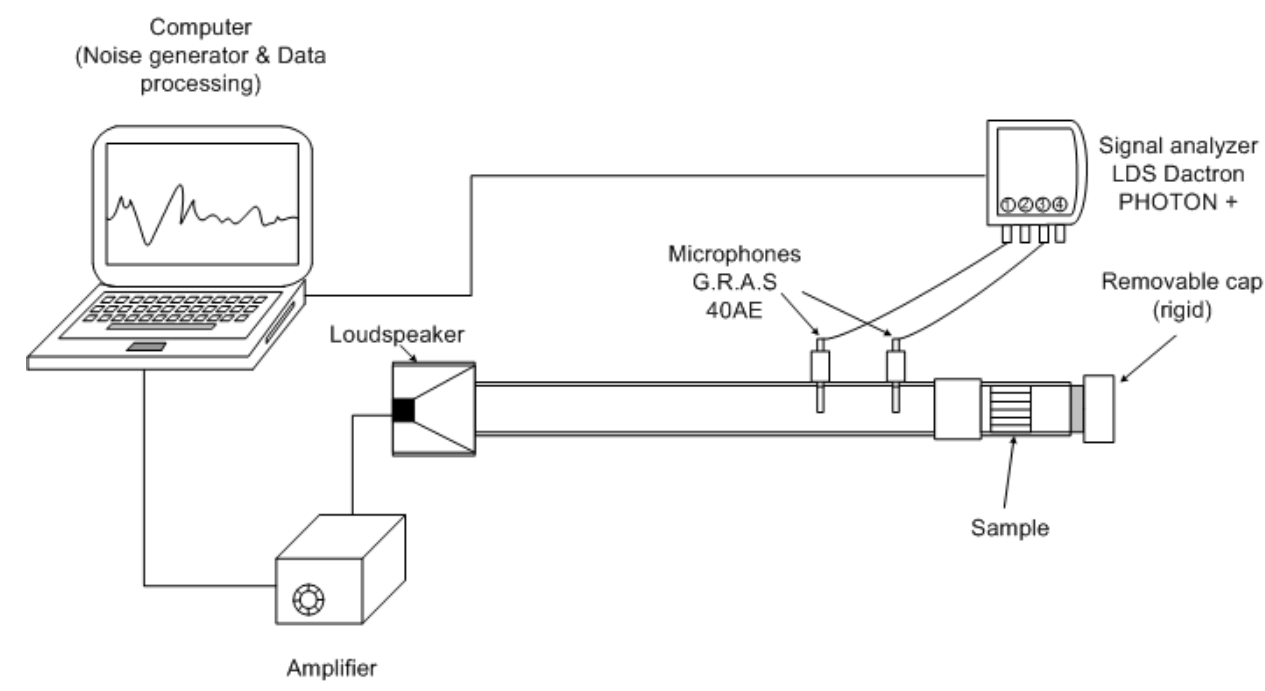

Figure 4. Schematic diagram of experimental set-up.

In general, the sound absorption coefficient, $\alpha$ is mathematically defined as the percentage of sound energy being absorbed by an acoustic material. It is a dimensionless quantity ranging from 0 to 1 and varies with frequency. Usually a material with an absorption coefficient value of $\alpha>0.5$ is considered as a good sound absorbed [29]. The general formula is given by

$$
\alpha=1-\frac{E_{r}}{E_{i}}
$$

where $E_{r}$ is the reflected energy and $E_{i}$ is the incident energy. Details of the formula for Eq. (1) in terms of the transfer function between signals recorded from the two microphones in the measurement can be referred in the ISO 10534-2 document.

\section{RESULTS AND DISCUSSION}

Measurements of the absorption coefficient for each arrangement were taken at least twice. For each measurement, the samples were detached and placed back into the place holder to ensure repeatability of the results. The final result is the averaged absorption coefficient from all the measurements. Figure 5 shows examples of the measured auto spectra signals from each acoustic microphone for samples in axial arrangement with lengths of $2 \mathrm{~cm}$ and $3 \mathrm{~cm}$. It can be seen that the variability is relatively small which also 
means minimum error in the results due to possible discrepancy in the sample arrangement in the tube which may affect the validity of the results.
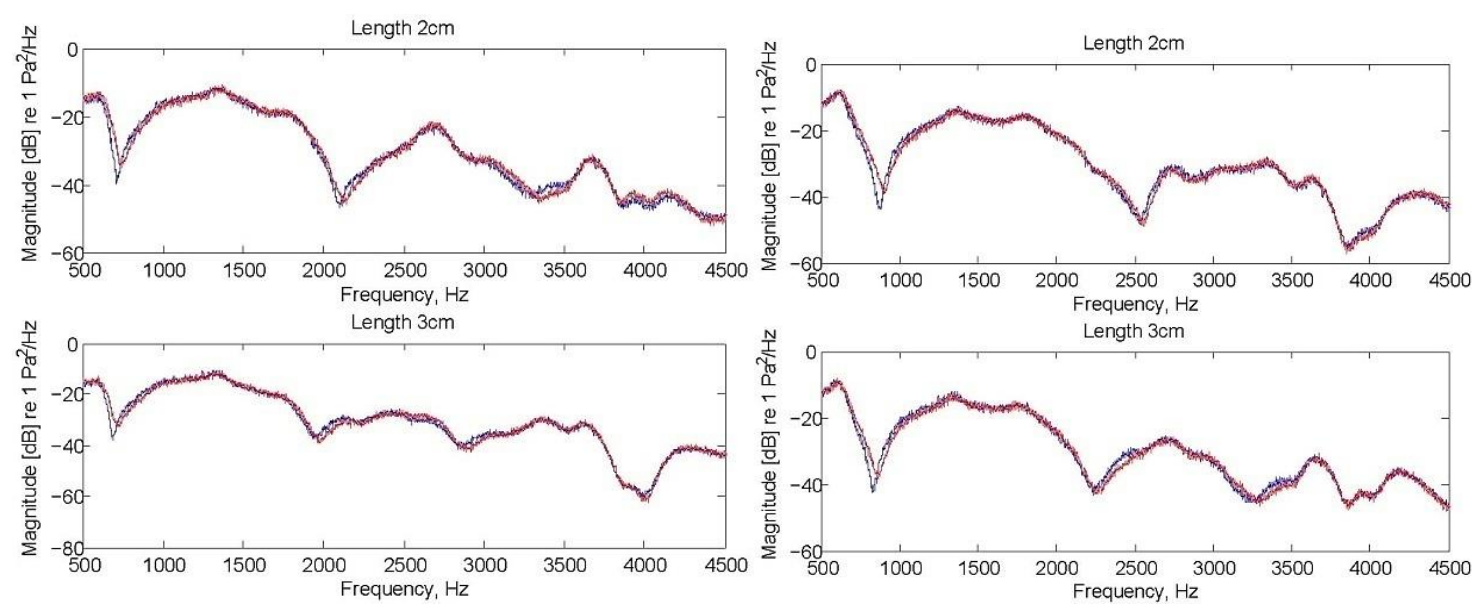

(a)

(b)

Figure 5. Measured signals of autospectra from the microphone: (a) closest to sample and (b) closest to loudspeaker.

Figure 6 shows the absorption coefficients of the hollow tube structures in three different arrangements. For the transverse arrangement, good absorption of $\alpha>0.5$ is only achieved at a bandwidth around the peak frequency with a peak level of $0.6-07$. Peak frequency corresponds to a quarter acoustic wavelength. The first peak in Figure 6(a) occurs in a frequency of around $f=4.1 \mathrm{kHz}$ which corresponds to the sample length of 2 $\mathrm{cm}$. The wavelength is $\lambda=c / f=343 / 4100=0.084 \mathrm{~m}$. Thus a quarter wavelength gives $(1 / 4) \lambda=0.021 \mathrm{~m} \approx 2 \mathrm{~cm}$ where $c=343 \mathrm{~m} / \mathrm{s}$ is the speed of sound in air. Similarly, in Figure 5(b) the sample with length $3 \mathrm{~cm}$ has the first peak frequency at $2.68 \mathrm{kHz}$, where $\lambda=343 / 2680=0.128 \mathrm{~m} \rightarrow(1 / 4) \lambda=0.032 \mathrm{~m} \approx 3 \mathrm{~cm}$. Therefore, the effect of increasing the length is that the peak frequency can be shifted to lower frequencies. Simple calculations above reveal the relationship between the length of the hollow tube and the frequency of the first peak which is due to the resonance effect where sound behaves as waves in a circular tube.

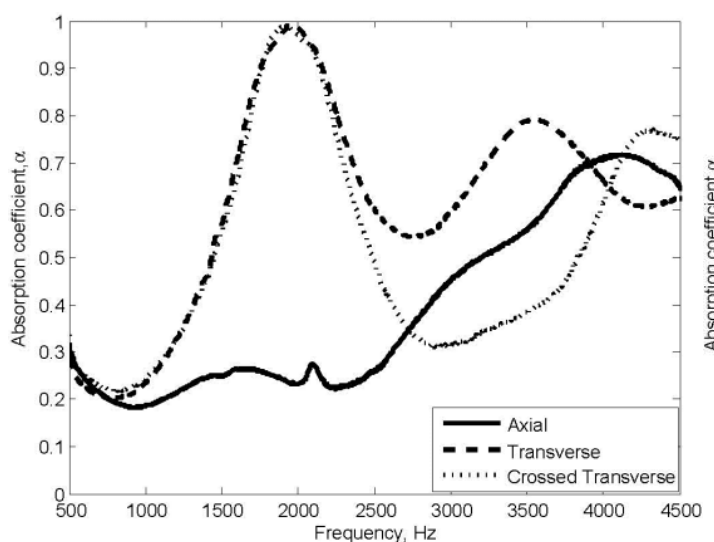

(a)

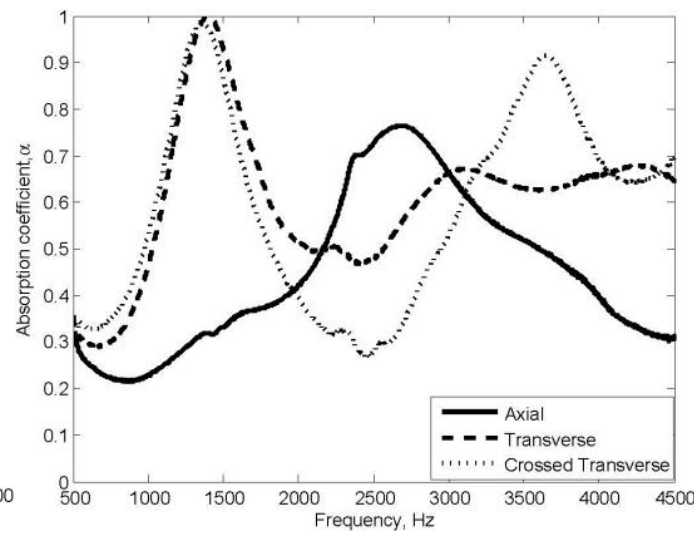

(b)

Figure 6. Absorption coefficients of hollow tubes of different arrangements in length or layer thickness: (a) $2 \mathrm{~cm}$ and (b) $3 \mathrm{~cm}$. 
For the transverse and crossed transverse arrangements, the absorption coefficient can be seen to significantly improve across the frequency with peak values to reach unity. Above the first peak frequency, the axial arrangement has an almost flat absorption at an average of 0.6 , but for the crossed transverse arrangement, the dip degrades its performance with an absorption coefficient of below 0.5 as a consequence of the standing wave effect[30]. Note that the second absorption peak which is suppressed in the transverse arrangement is more obvious in the crossed transverse arrangement as shown in Figure 6(b). The mechanism of sound absorption for the transverse arrangement takes place around the air gap along the circumference of the tube. After penetrating the air gap, the sound then propagates in a horizontal direction inside the hollow path in the sample. A small amount of sound energy is also absorbed through the gap between the body structures by means of frictional loss. However, unlike the axial arrangement, both the transverse and crossed transverse arrangements have the first peak of absorption at a frequency of around half the peak frequency of the axial arrangement. This indicates the half-wavelength $(1 / 2) \lambda$ relationship. For the transverse arrangement, the second peak is repeated at roughly twice the frequency of the first peak, although with a lower amplitude. Meanwhile for the crossed transverse arrangement, the second peak appears at a higher frequency indicating different wavelength relationships. This is due to a more complicated sound path inside the sample.

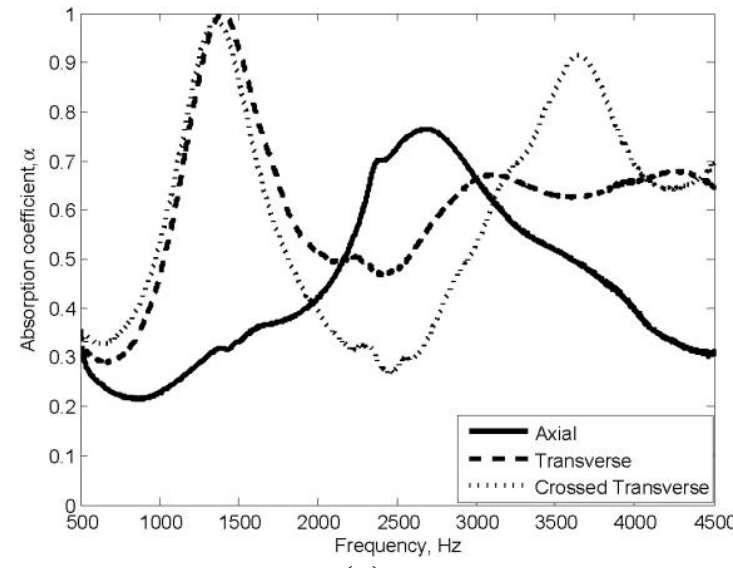

(a)

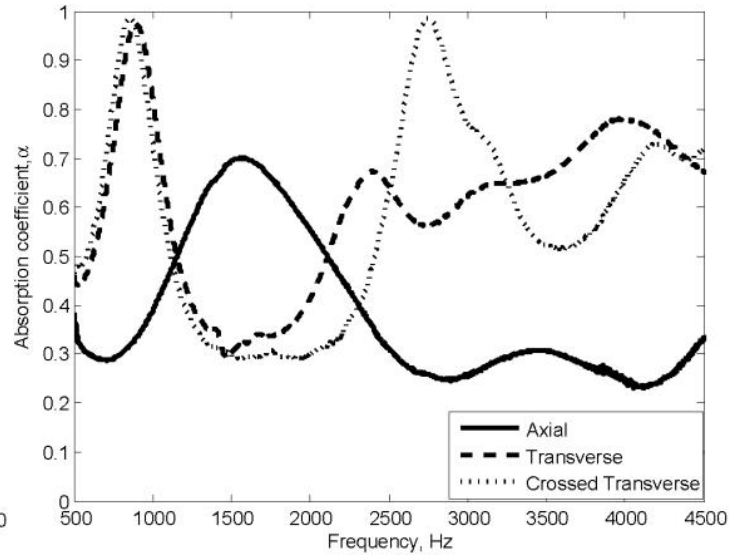

(b)

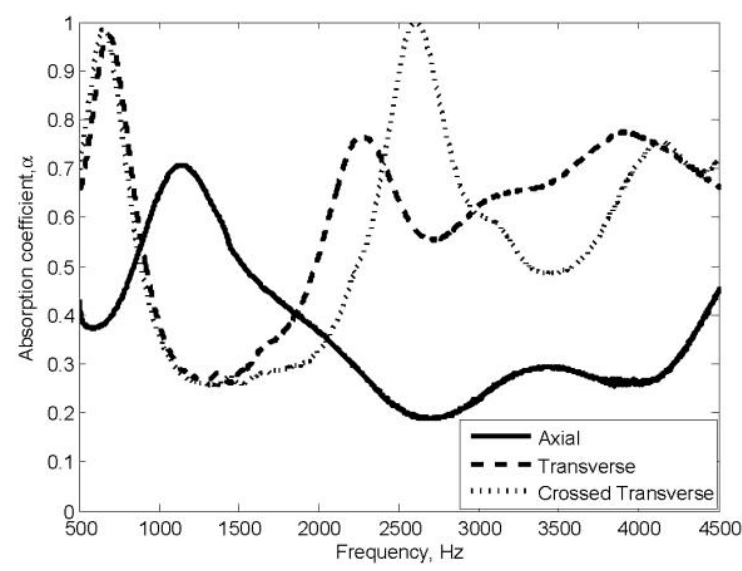

(c)

Figure 7. Absorption coefficient of $3 \mathrm{~cm}$ hollow tubes of different arrangements for different air gaps: (a) $D=0 \mathrm{~cm}$, (b) $D=1 \mathrm{~cm}$ and (c) $D=2 \mathrm{~cm}$. 
Effect of adding air gaps behind the sample is plotted in Figures 7 and 8. Results showed that the absorption peak shifts to a lower frequency as the air gap is increased due to additional viscous dissipation from the air depth [30]. For the axial arrangement, the presence of air gap $D$ creates a phenomenon whereas if $2 D$ length is added to the total length of the tube it takes into account the dissipation around the opening of the tube [31]. For example, in Figure 7(b) for air gap of $D=1 \mathrm{~cm}$, the total length is $2 \mathrm{~cm}+(2 \times 1 \mathrm{~cm})$ $=4 \mathrm{~cm}$. This corresponds to the quarter wavelength, where $(1 / 4) \lambda=0.04 \mathrm{~m} \approx 0.16 \mathrm{~m}$. The peak frequency is thus $f=c / \lambda=343 / 0.16 \approx 2.1 \mathrm{kHz}$. The same is also applied for air gap of $D=2 \mathrm{~cm}$ in Figure 7(c) which results in peak frequencies of around $1.4 \mathrm{kHz}$. The peak frequencies can also be found using a similar calculation for a tube length of $3 \mathrm{~cm}$ as in Figure 8. Similarly, for the rigid backing discussed in the results in Figure 6, the transverse and crossed transverse arrangements with the air gap, the peak frequency also appears at roughly half the peak frequency for the axial arrangement. Again, the crossed transverse arrangement can be seen to have distinct second peaks as compared to the transverse arrangement especially for results with the air gap. Both have the same dips above the first peak frequency at twice the frequency with an absorption coefficient of below 0.5 especially for those with air gap introduction. This must be noted when designing a target frequency for the absorber. Above this dip frequency, the transverse arrangement has an almost flat absorption coefficient of 0.6 on average throughout the frequency, while the crossed arrangement has a distinct second peak followed by a dip. However, the absorption coefficient is still above 0.5 .

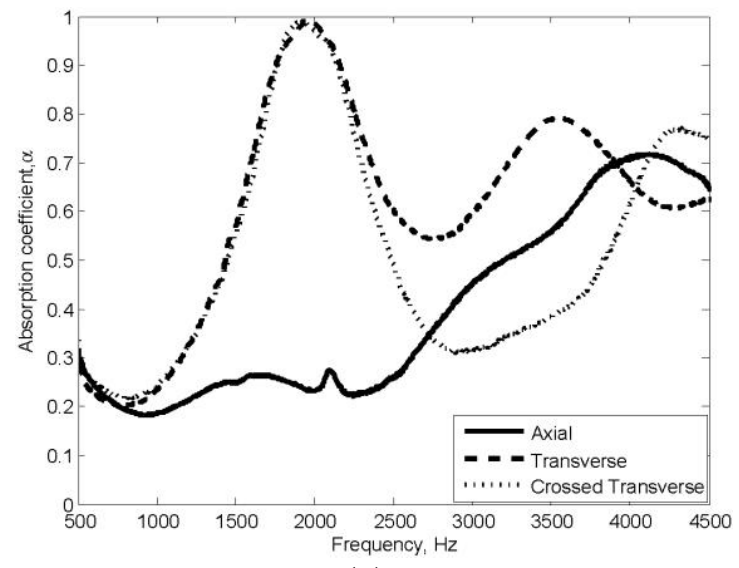

(a)

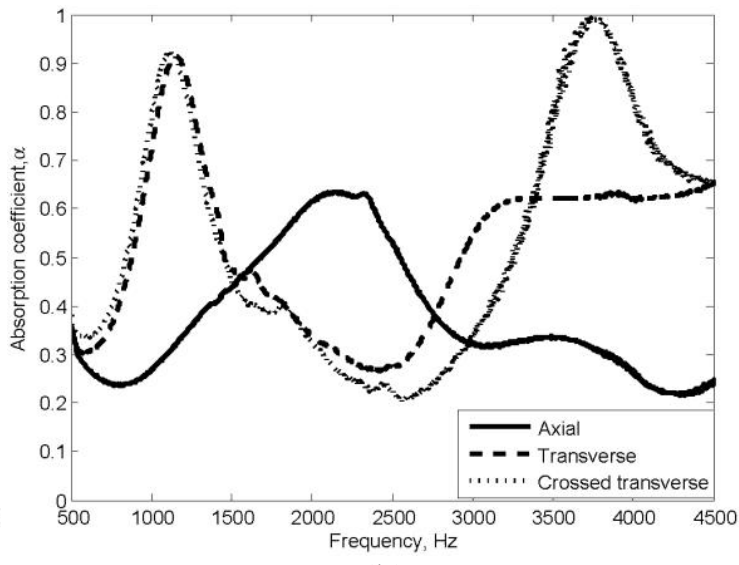

(b)

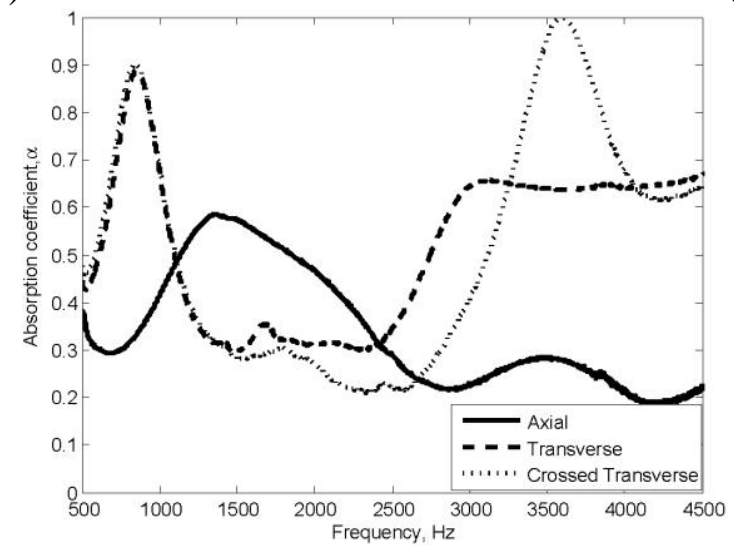

(c)

Figure 8. Absorption coefficients of $2 \mathrm{~cm}$ hollow tubes of different arrangements for different air gaps: (a) $D=0 \mathrm{~cm}$, (b) $D=1 \mathrm{~cm}$ and (c) $D=2 \mathrm{~cm}$. 
Figure 9 shows the effects of the fabric covering the front, back and both sides of the sample in axial arrangement. The combination of the fabric with the hollow tubes not only results in enhancement of the absorption coefficient levels, but also widens the absorption bandwidth frequency. According to Fouladi, Nor [15], having porous materials in front of the sample can enhance the level of absorption coefficient, while absorption at lower frequency can be improved with porous material at the back of the sample. As shown in Figure 9, the sample backed with fabric has a peak frequency shifting to a lower frequency. It was found that a single layer covering the front surface of the sample was sufficient to improve sound absorption.

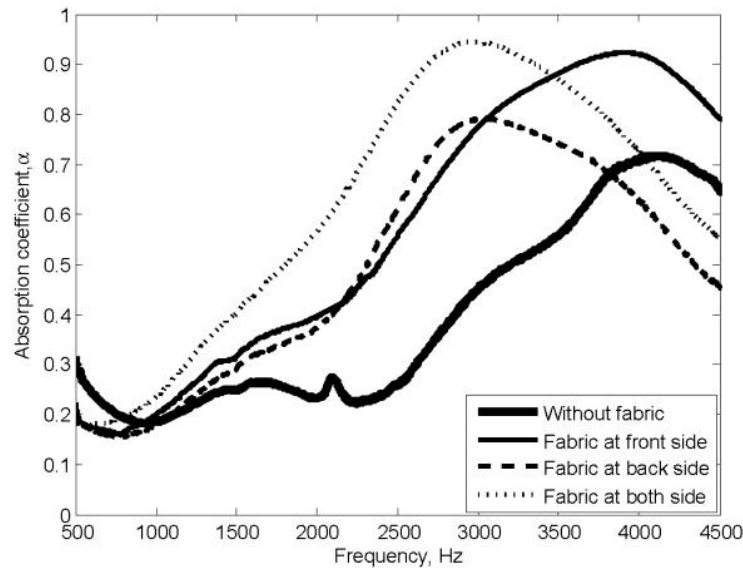

(a)

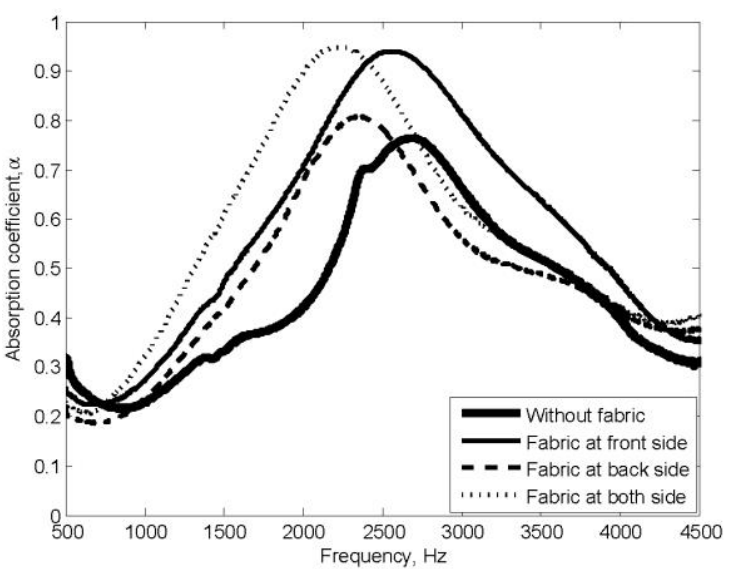

(b)

Figure 9. Absorption coefficient of hollow tubes with length: (a) $2 \mathrm{~cm}$ and (b) $3 \mathrm{~cm}$ in axial arrangement with attachment of fabric.

For transverse and crossed transverse arrangements with the addition of fabric, its effect on sound absorption is generally insignificant as shown in Figures 10 and 11. This indicates that sound energy is mainly dissipated inside the tubes after penetrating the front cover or before reaching the back cover of the fabric. This is also consistent with the results for bamboo materials discussed by Putra, Khair [27].

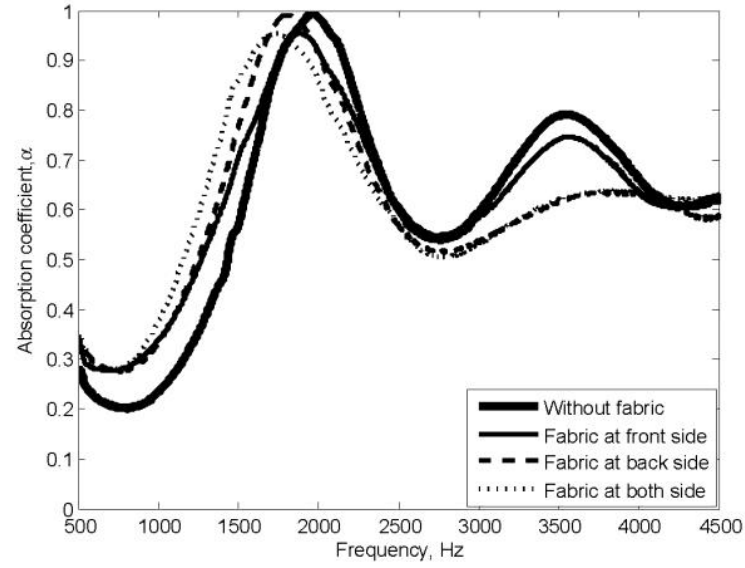

(a)

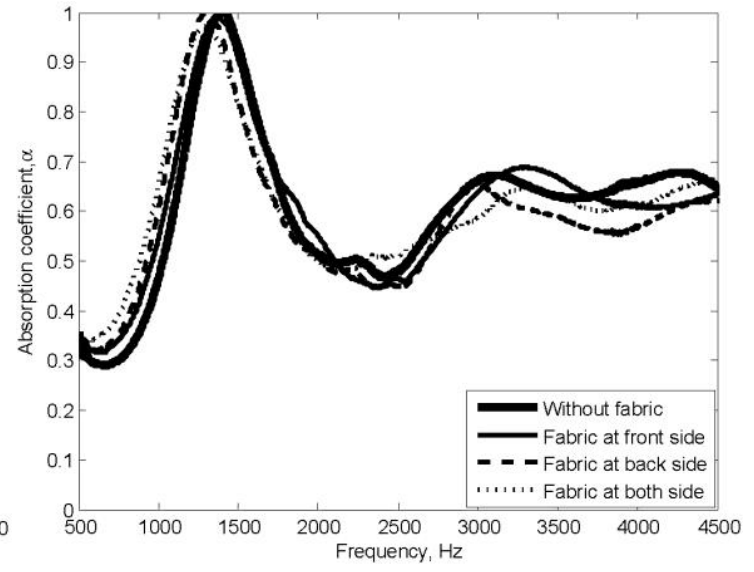

(b)

Figure 10. Absorption coefficients of hollow tubes with layer thickness: (a) $2 \mathrm{~cm}$ and (b) $3 \mathrm{~cm}$ in transverse arrangement with attachment of fabric. 


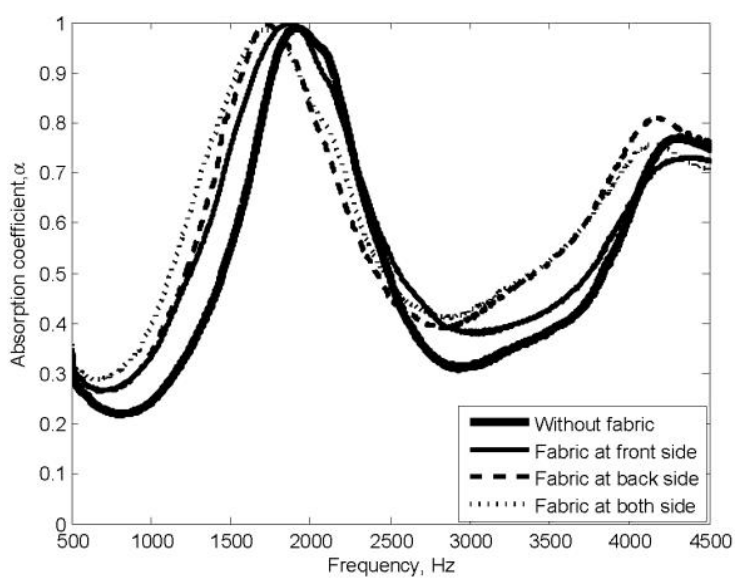

(a)

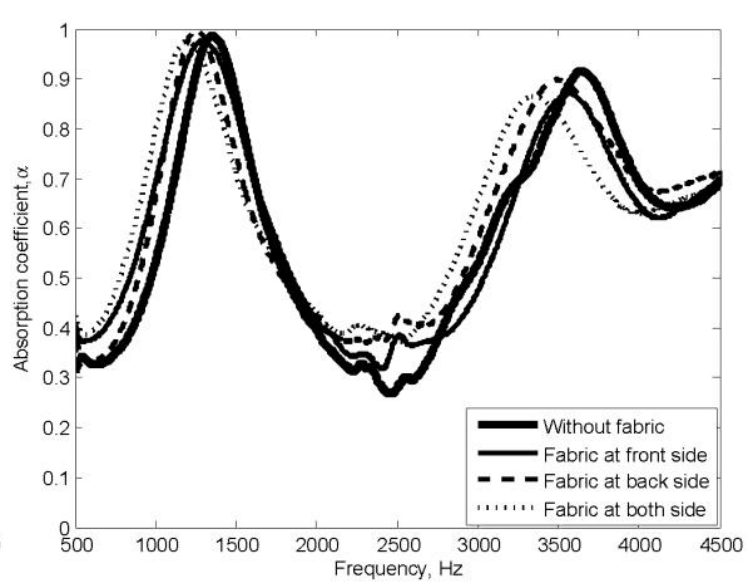

(b)

Figure 11. Absorption coefficients of hollow tubes with layer thickness: (a) $2 \mathrm{~cm}$ and (b) $3 \mathrm{~cm}$ in crossed transverse arrangement with attachment of fabric.

\section{CONCLUSIONS}

Acoustic performance of sound absorbers from hollow tube structures utilising waste lollipop sticks was measured. The tubes in transverse and crossed transverse arrangements showed significant improvement in sound absorption as compared to the axial arrangement. With a layer thickness of 2 and $3 \mathrm{~cm}$, the absorption peak can reach unity and the average absorption coefficient was 0.6 above peak frequency. Peak frequency can be controlled through wavelength relationships corresponding to the length of the tube. The introduction of air gap shifts the peak to a lower frequency. The introduction of fabric cover improves the absorption of the axial arrangement with the back cover shifting peak frequency to a lower frequency. However, no significant effect was found on introducing fabric for transverse and crossed transverse arrangements. It is also of interest to study the sound performance of similar hollow tube structures, especially those from waste materials in order to contribute in saving the environment. Measurement data of sound absorption subjected to random incidents of sound fields is also important to obtain a comprehensive study of the acoustical characteristics of hollow tube structures.

\section{ACKNOWLEDGEMENTS}

This project is funded by the Ministry of Higher Education (MoHE), Malaysia under the Exploratory Research Grant Scheme No. ERGS/1/2013/STG02/UTEM/02/01. Acknowledgement is also addressed to Universiti Teknikal Malaysia Melaka (UTeM) for the financial support through Zamalah Scholarship as well as for the valuable discussion with colleagues in VibroResearch Group, CARe.

\section{REFERENCES}

[1] Asdrubali F, Schiavoni S, Horoshenkov K. A review of sustainable materials for acoustic applications. Building Acoustics. 2012;19:283-312.

[2] Wan Dalina WAD, Mariatti M, Mohd Ishak ZA, Mohamed AR. Comparison of properties of mwcnt/carbon fibre/ epoxy laminated composites prepared by 
solvent spraying method. International Journal of Automotive and Mechanical Engineering. 2014;10:1901-9.

[3] Abdul Majid MS, Daud R, Afendi M, Amin NAM, Cheng EM, Gibson AG, et al. Stress-strain response modelling of glass fibre reinforced epoxy composite pipes under multiaxial loadings. Journal of Mechanical Engineering and Sciences. 2014;6:916-28.

[4] Ravi Sankar H, Srikant RR, Vamsi Krishna P, Bhujanga Rao V, Bangaru Babu P. Estimation of the dynamic properties of epoxy glass fabric composites with natural rubber particle inclusions. International Journal of Automotive and Mechanical Engineering. 2013;7:968-80.

[5] Putra A, Abdullah Y, Efendy H, Mohamad W, Salleh NL. Biomass from paddy waste fibers as sustainable acoustic material. Advances in Acoustics and Vibration. 2013;2013.

[6] Putra A, Abdullah Y, Efendy H, Farid WM, Ayob MR, Py MS. Utilizing sugarcane wasted fibers as a sustainable acoustic absorber. Procedia Engineering. 2013;53:632-8.

[7] Eriningsih R. Flax fiber composites and waste of hemp as a sound absorption material (in indonesian). Arena Textiles. 2009:51-9.

[8] da Silva GM, de Castro Magalhães M, Guerra A. Comparative study of sound absorption systems composed of multilayered panels.

[9] Kim B-S, Cho S-J, Min D-K, Park J. Sound absorption structure in helical shapes made using fibrous paper. Composite Structures. 2015;134:90-4.

[10] Ersoy S, Küçük H. Investigation of industrial tea-leaf-fibre waste material for its sound absorption properties. Applied Acoustics. 2009;70:215-20.

[11] Veerakumar A, Selvakumar N. A preliminary investigation on kapok/ polypropylene nonwoven composite for sound absorption. Indian Journal of Fibre \& Textile Research. 2012;37:385-8.

[12] Ismail L, Ghazali MI, Mahzan S, Zaidi AMA. Sound absorption of Arenga Pinnata natural fiber. World Academy of Science, Engineering and Technology. 2010;67:804-6.

[13] Zulfian Z, Sajidin M. Kajian tentang kemungkinan pemanfaatan bahan serat ijuk sebagai bahan penyerap suara ramah lingkungan. Jurnal Rekayasa Kimia \& Lingkungan. 2009;7.

[14] Fouladi MH, Ayub M, Nor MJM. Analysis of coir fiber acoustical characteristics. Applied Acoustics. 2011;72:35-42.

[15] Fouladi MH, Nor MJM, Ayub M, Leman ZA. Utilization of coir fiber in multilayer acoustic absorption panel. Applied Acoustics. 2010;71:241-9.

[16] Rozli Z, Zulkarnain Z. Noise control using coconut coir fiber sound absorber with porous layer backing and perforated panel. American Journal of Applied Sciences. 2010;7:260-4.

[17] Ying LZ, Putra A, Nor MJM, Muhammad N, Yaakob MY. Sound absorption of multilayer natural coir and kenaf fibers. 23rd International Congress on Sound \& Vibration. 2016; 1-7.

[18] Ismail AE, Che Abdul Aziz MA. Tensile strength of woven yarn kenaf fiber reinforced polyester composites. Journal of Mechanical Engineering and Sciences. 2015;9:1695-704.

[19] Umar AH, Zainudin ES, Sapuan SM. Effect of accelerated weathering on tensile properties of kenaf reinforced high-density polyethylene composites. Journal of Mechanical Engineering and Sciences. 2012;2:198-205. 
[20] Mat Hassan NN, M. Rus AZ. Acoustic Performance of green polymer foam from renewable resources after UV Exposure. International Journal of Automotive and Mechanical Engineering. 2014;9:1639-48.

[21] Francesco A, Francesco DA, Nicholas M. Sound absorption properties of tropical plants for indoor applications. 21st International Congress on Sound and Vibration: International Institute of Acoustics ad Vibration; 2014.

[22] Bastos LP, de Melo GdSV, Soeiro NS. Panels manufactured from vegetable fibers: An alternative approach for controlling noises in indoor environments. Advances in Acoustics and Vibration. 2012;2012.

[23] Asdrubali F, D'Alessandro F, Schiavoni S, Mencarelli N. Sound absorption properties of reed. Proceedings of the 22nd International Congress on Sound and Vibration, Florence, Italy2015.

[24] Oldham DJ, Egan CA, Cookson RD. Sustainable acoustic absorbers from the biomass. Applied Acoustics. 2011;72:350-63.

[25] Khair F, Putra A, Nor M, Atiqah N. Investigation on reed Imperata Cylindrica as sound absorber. Proceedings of Mechanical Engineering Research Day 2015. 2015;2015:91-2.

[26] Khair F, Putra A, Nor M, Selamat M. Enhancement on acoustical performance of reed'Imperata Cylindrica'. Proceedings of Mechanical Engineering Research Day 2016. 2016;2016:192-3.

[27] Putra A, Khair FA, Nor MJM. Utilizing hollow-structured bamboo as natural sound absorber. Archives of Acoustics. 2015;40:601-8.

[28] Standard B. Acoustics-determination of sound absorption coefficient and impedance in impedance tubes-Part 2: Transfer Function Method. BS EN ISO. 2001:10534-2.

[29] Dah-You M. Theory and design of microperforated panel sound-absorbing constructions. Scientia Sinica. 1975;18:55-71.

[30] Everest Alton F. The master handbook of acoustics. Mc Graw Hill; 2001.

[31] Putra A. Sound radiation from perforated plates. Doctoral dissertation, University of Southampton. 2008. 